\title{
The Impact of Purchase Restriction Policy on Car Ownership in China's Four Major Cities
}

\author{
Feiqi Liu, ${ }^{1,2}$ Fuquan Zhao, ${ }^{1,2}$ Zongwei Liu, ${ }^{1,2}$ and Han Hao ${ }^{10,2,3}$ \\ ${ }^{1}$ State Key Laboratory of Automotive Safety and Energy, Tsinghua University, Beijing 100084, China \\ ${ }^{2}$ Tsinghua Automotive Strategy Research Institute, Tsinghua University, Beijing 100084, China \\ ${ }^{3}$ China Automotive Energy Research Center, Tsinghua University, Beijing 100084, China
}

Correspondence should be addressed to Han Hao; hao@tsinghua.edu.cn

Received 18 July 2019; Revised 28 November 2019; Accepted 11 December 2019; Published 22 January 2020

Academic Editor: Shamsunnahar Yasmin

Copyright (c) 2020 Feiqi Liu et al. This is an open access article distributed under the Creative Commons Attribution License, which permits unrestricted use, distribution, and reproduction in any medium, provided the original work is properly cited.

With the improvement of living standards, the demand for residents' travel has grown rapidly. At present, China has surpassed the U.S. to become the world's largest vehicle sales country. By the end of 2018, there had been over 200 million private passenger cars in China. Meanwhile, the increase in the number of cars has also brought a series of other problems: energy consumption, air pollution, traffic congestion, etc. Therefore, some first-tier cities have successively introduced motor vehicle purchase restriction policies to constrain the surge of local private cars. However, existing researches have overemphasized the factors that promote the development of China's motor vehicle market and ignored the importance of the purchase restriction policies. In this study, policies in Beijing, Tianjin, Shanghai, and Guangzhou are introduced, and their impacts on local private passenger car stock are analyzed. The results indicate that purchase restriction policies kept the car ownership per thousand people in these cities in a relatively stable level with growing economy. Therefore, as the number of cities with restriction policies increases, it is necessary to take those policies into consideration in the forecast of possession. Meanwhile, the local governments should still think over policy contents from more aspects, like number of issued plates every year, special measures for new energy vehicles, and travel demand of residents.

\section{Introduction}

The development of vehicle industry leads to great concerns about life quality, energy, environment, infrastructure construction, etc. [1]. Vehicle sales and stock grow quickly with the surge of economy and life quality. Especially in developing countries, vehicles can not only meet the travel demand but also represent wealth and identity [2]. Therefore, more and more people become interested in vehicle ownership. Meanwhile, the rapid growth of vehicle stock (vehicle population) brings problems. Large amount of oil consumption has contributed to energy security and greenhouse gas (GHG) emissions. Based on the research of International Energy Agency (IEA), 20\% GHG emissions come from road transportation in 2015 [3]. At the same time, traffic congestion becomes another critical problem. More and more time is wasted on daily commuting. According to the report from Beijing Transport Institute, in Beijing, average traffic jam time reached 2 hours and 40 minutes every day in 2017 [4]. Though increasing vehicle stock is not the only trigger for all of these problems, it must be one of the most significant reasons.

Therefore, many researches have been done to analyze and predict the development trends of vehicle sales or stock, and some are used as the basic assumption for further studies, like energy consumption or GHG emissions of vehicle fleet. Some studies found the laws and provided the prediction of vehicle stock in household level, because data are relatively comprehensive and available from household surveys and it could point out regional differences [5-8]. Meanwhile, some researches are focused on national level analyzation, and some China cases have been analyzed in the provincial level [9-20]. These ones are based on fewer variables and made the prediction from a macroperspective 
without much consideration of diversities in individual behavior.

Most of the researches are based on economic development level, as shown in Table 1 [5-23]. Vehicle ownership per thousand people is almost always mentioned with gross domestic production (GDP) per capita $[10,11,16-20]$. It is treated as a reliable variable to forecast vehicle growth curve. However, the previous studies always only included positive factors, like economic index, population, urbanization level, and so on, and ignored the limitation factors in vehicle stock.

In China, the passenger vehicle stock exceeded 200 million at the end of 2018, with an annual growth rate of $11.56 \%$ [24]. While, in 2018, the sales of passenger vehicles in China experienced its first drop in the past several decades [25]. As shown in Figure 1, the vehicle ownership per thousand people in China still remains in a relatively low level [26]. Compared with the previous prediction, there is great potential for the market to reach a saturation level or equal to that of developed countries [18, 27-29]. Due to the vast territory, there is also great differences in economy development level and consumptive habit in the provincial level. Thus, the vehicle stock also reflects great variation.

The drop of sales was partly due to the slowdown in economic growth. Another reason that is easily overlooked is the purchase restriction in some first-tier cities. Few studies pay attention to these special cities. Because the policies are always applied in the city level, it is hard to see the effects in provincial level, except for in municipalities directly under the Central Government, not to mention the national level. As shown in Figure 2, the effects of vehicle purchase limitation are eminent in Beijing and Tianjin [26]. As more and more cities begin to introduce vehicle purchase restriction policies, it becomes necessary to evaluate the impacts of these policies on vehicle stock or sales.

Some studies did focus on the purchase restriction policies in China. Shi and Jian compared vehicle stocks in two cities in China, Beijing, and Huhhot, under with and without car purchasing restriction policy scenarios [27]. The Gompertz method was applied in their study. However, there are some problems in the study. First, based on the analysis of Wang's research, it is unreasonable to use other countries' vehicle stock prediction model directly into China's case [17]. There is great difference in time period for GDP and automotive development. Second, the purchasing restriction policies in Beijing varied every year. The vehicle stock, especially passenger vehicle stock, depends almost entirely on the number of plates issued every year by the government. Predicting the future based on past or existing policies is inaccurate. Besides, it is also not proper to apply Gompertz model under restriction circumstance. S curve is no longer applicable due to the policy intervention. Finally, the authors took Huhhot as an example to study the purchase behavior. The possibility of limiting purchases in second-tier cities in short term is very low, and the choice from residents is not representative. Hao et al. compared the policies' impact on Beijing and Shanghai [13, 14]. While, when the article was published, Beijing had not adopted actions to limit car plate numbers. The study was based on the authors' assumption, and it is not applicable now. Feng et al. evaluated the performance of purchase restriction policy in Shanghai by comparing the vehicle stock in Shanghai with three similar areas [30]. The results indicated that the annual growth rate of private car ownership had dropped by $30 \%$ since 2003 . Whereas more cities have begun to limit the number of vehicle plates and policies vary from each other. It is necessary to make a more comprehensive analysis and provide recommendations to policymakers.

In conclusion, vehicle stock plays an important role in future development of automotive industry and prediction of other related areas, while the previous studies pay much attention on the relationship between car ownership and economic index. Purchase restriction policies gradually have great impacts on vehicle stock. The objective of this study is to evaluate the influence of this kind of policies on vehicle stock. Four cities are chosen as examples, Beijing, Tianjin, Shanghai, and Guangzhou. Section 2 introduces the details of vehicle purchase restriction policies in each city. The following parts show methods and data. The fourth one exhibits the results and analyzation of policy impacts and provides some recommendations. The last part summarizes the whole research.

\section{Passenger Vehicle Purchase Restriction Policies in China}

Shanghai is the first city to introduce passenger vehicle purchasing restriction policies in China. So far, eight cities have issued related policies, Shanghai in 1994, Beijing and Guiyang (urban area) in 2011, Guangzhou in 2012, Tianjin in 2013, Shenzhen and Hangzhou in 2014, and Hainan in 2018. Due to the data availability and policy characteristics, four cities, Beijing, Tianjin, Shanghai, and Guangzhou, are chosen as typical ones and purchasing restriction policies in these cities are analyzed in this study.

2.1. Beijing. At the end of 2010, to orderly control the number of passenger vehicles, alleviate traffic congestion, and reduce the energy consumption, People's Government of Beijing Municipality decided to implement control measures on vehicle numbers $[31,32]$. Based on the rules, the car plates would be allocated in lottery without any fee in limited number every year. With the deployment of electric vehicles, the queue system was applied to new energy cars and plates for other types of vehicles still need to be luckily picked. According to the management regulations, only battery electric vehicles are treated as "new energy vehicles" in Beijing. Plug-in hybrid electric vehicles are listed in general quota.

The number of plates released every year is shown in Figure 3. In the first three years, the lottery results were released every month, and starting in 2014, dual-month selection was applied. Based on the total number of plates issued every year, the quantity control is getting stricter. In 2011, the government launched 245,610 plates in total, but in 2018 , there were only 96,874 plates available. Passenger cars for private-use and business-use are separated in lottery, private cars account for more gradually. Nowadays, it became harder and harder for people living in Beijing to get a 
TABle 1: Previous researches about vehicle stock.

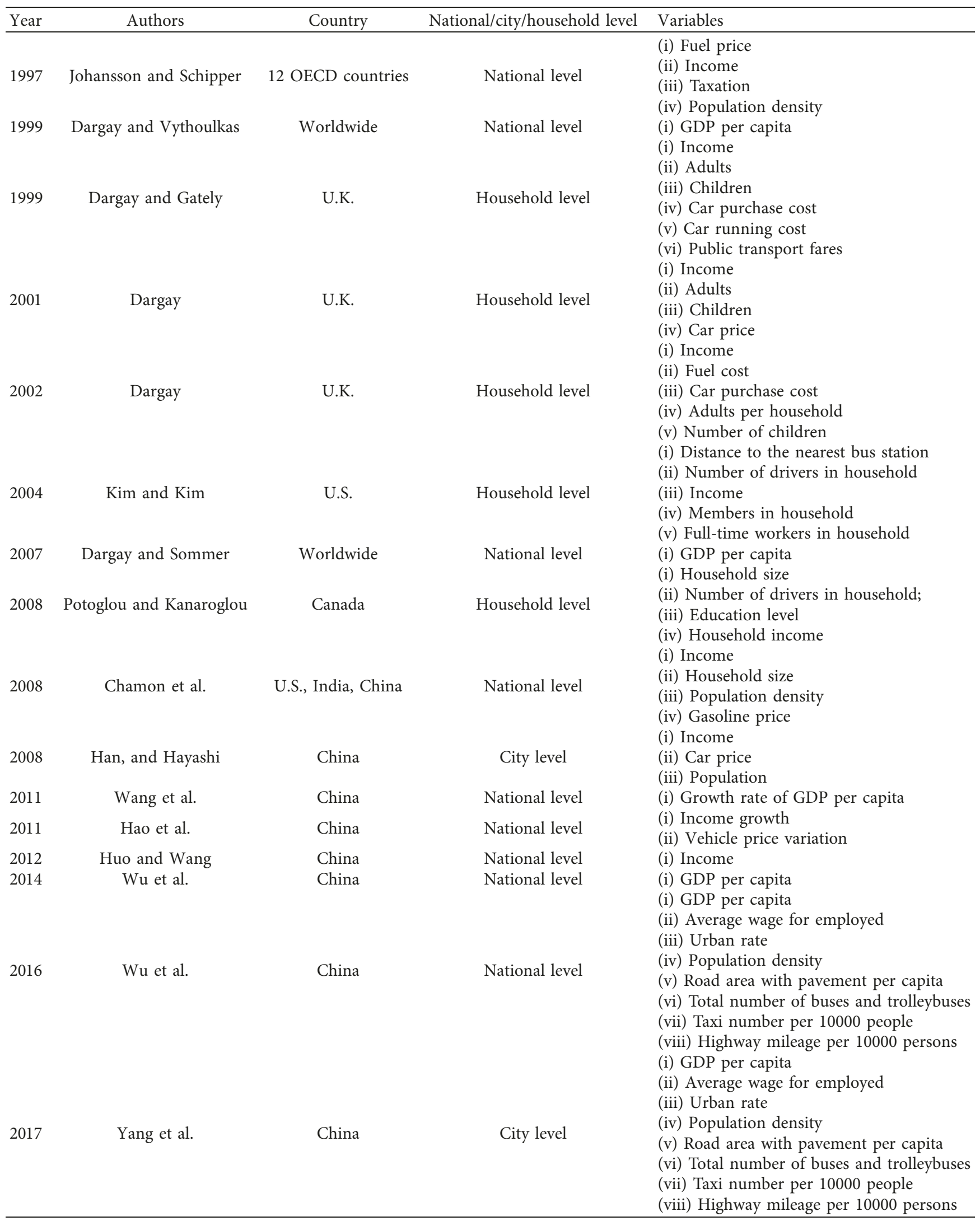


TABLE 1: Continued.

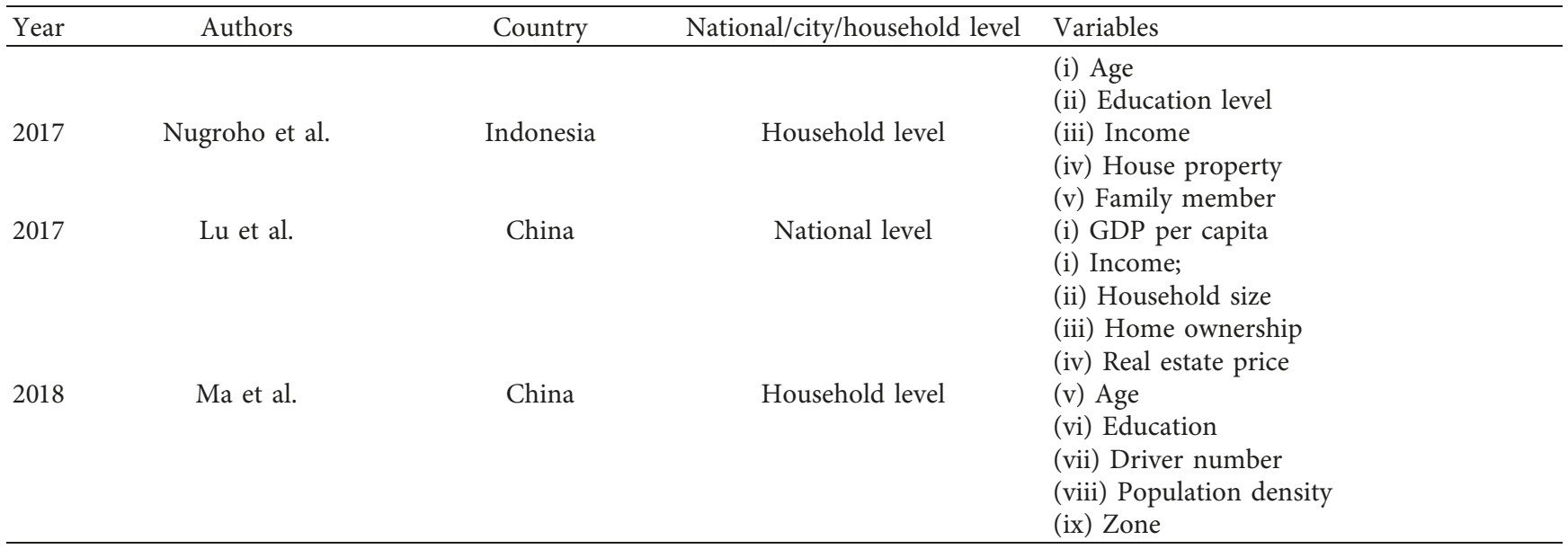

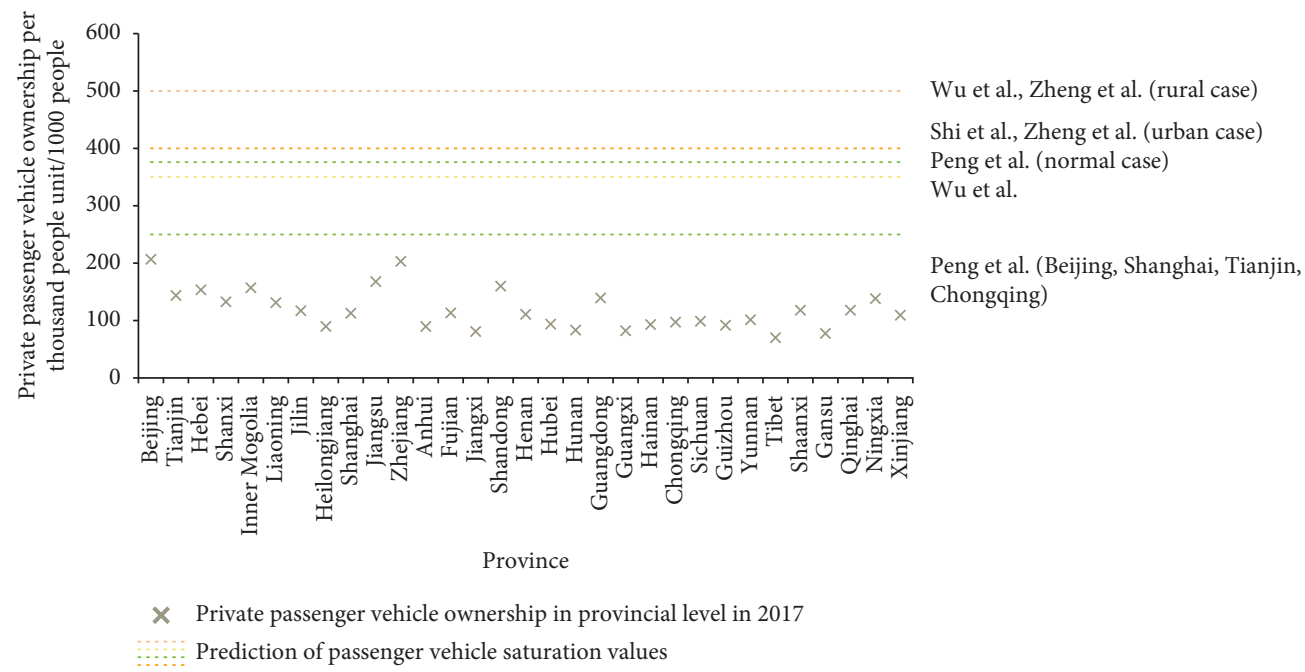

Figure 1: Private passenger vehicle ownership per thousand people in provincial level in China and some predictions of passenger vehicle saturation values in China.

license plate. In the last batch of lottery in 2018 , the number of valid codes was 14,620,617, and there are only 6413 allocated plates for conventional vehicles. People who apply for private-use vehicle plates have to meet the requirement shown in Figure 4. Besides, there must be no number plates in applicant's name, no matter traditional car plate, or new energy vehicle plate. That means since the regulation was released, one driver can only get one plate at most.

As for new energy vehicles, buyers have to wait one by one for plates. Meanwhile, the number of plates released every year is limited in certain number. The proportion of new energy vehicles in total quota increased dramatically since 2014, from $13 \%$ in 2014 to $59 \%$ in 2018 . Actually, before 2017, people could easily get the new energy vehicle plate as they wanted, because few people paid attention to electric cars, while, since the beginning of 2017, the demand began to exceed supply. By the end of 2018, there were 421,536 people waiting for the new energy vehicle plates. The number of new energy vehicle plate released in 2018 was 54,000. That means the latest people has to wait 7.8 years in queue, according to current status.
2.2. Tianjin. Tianjin as another province-level municipality set vehicle purchase limits in 2014 [33]. The regulation in Tianjin differentiates from that in Beijing. Lottery and auction mechanisms both exist in Tianjin. As for plate lottery, residents can get plates for free, but with luck. As for auction, the lowest price is given by the government. For example, it was 10,000 RMB in the last batch auction in 2018 in Tianjin. The bidders have two chances to alter the price during the auction process. "New energy vehicles" are still entitled to special treatment. Individuals and units can get plates for new energy vehicles directly, and unlike Beijing, there are no number limits.

The number of plates released every year maintain growth. There is a $16.6 \%$ growth from 2014 to 2018 as shown in Figure 5. The categories are more detailed in Tianjin. Private and business passenger car plates are allocated separately. Besides, two pools are independently for lottery, one for conventional cars and one for energy-saving vehicles (ESV) to promote the deployment of energy-saving ones. The model list of energy-saving cars is provided by Tianjin 


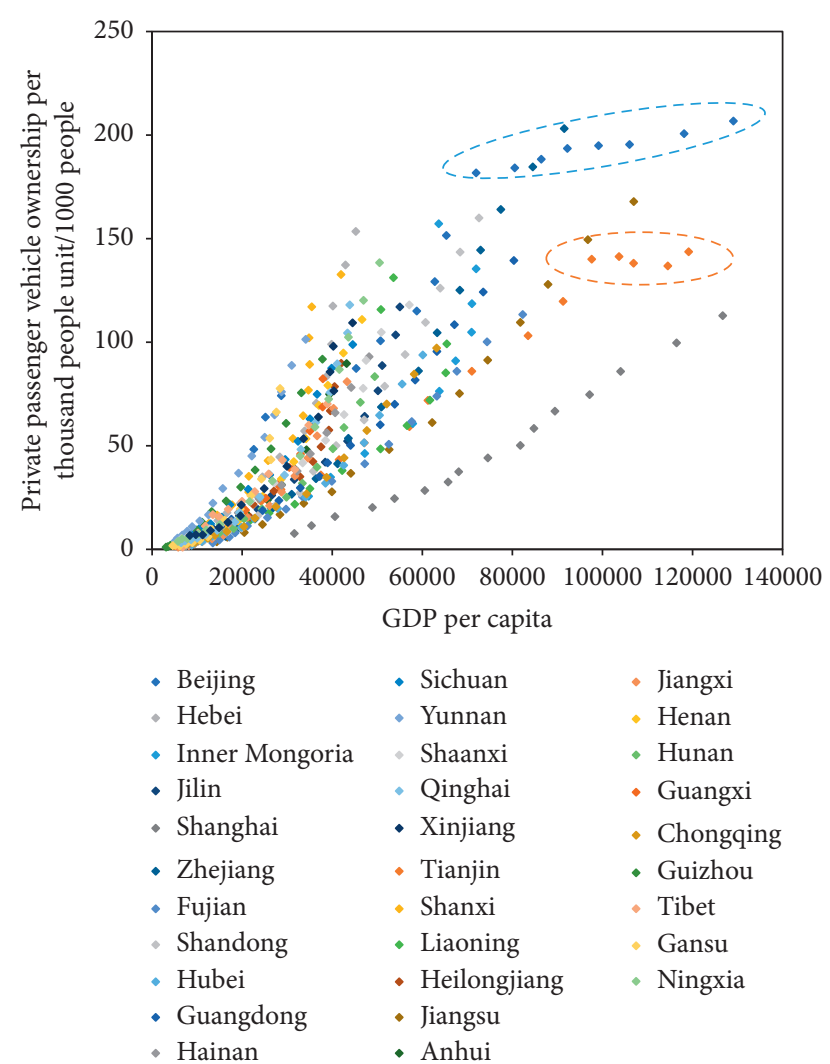

FIgURe 2: Private passenger vehicle ownership per thousand people based on GDP per capita from 2002 to 2017.

government. The cars have to be hybrid vehicles with over $20 \%$ fuel consumption saving or be included in the recommendation catalogues issued by Ministry of Industry and Information Technology of the People's Republic of China (MIIT). Partly due to the higher price, at the first two years, 2014 and 2015, the quota for personal energy-saving car was surplus. After 2016, people began to scramble for both plates. Just like Beijing, the applicants also are asked to have no vehicles before the application for another plate of traditional car. However, no limitation is required for new energy plates.

Auction is a measure totally different from lottery. The proportion of auction in total keeps relatively stable over the past three years. People who involve in auction can solve the mobility problem through market means. However, quantitative restriction still exists. Only most emergency buyers can get plates and the government still have the control of vehicle numbers. The prices of private and business plate reflect different trends, as shown in Figure 6. The price of private goes through serious fluctuation, and private plates ask for higher price than business ones.

2.3. Shanghai. Shanghai is the first city introducing car purchase limitation in 1994. As the important center of economy and finance, Shanghai government controls the vehicle number by auction $[34,35]$. The requirement for applicants is shown in Figure 4. Due to the growth of living standards, residents' demand for car increases accordingly.
Thus, the price of plates rises dramatically, from around 15,000 RMB in 2002 to around 90,000 in 2018 as shown in Figure 7 . The number of plates released every year follows a growing trend, though there was a drop in 2014 and 2015. However, compared to other cities, the number of plates in Shanghai still are controlled in a relatively low level. As for the new energy vehicle plates, residents in Shanghai without electric vehicle plates can apply for one for free. Battery electric vehicle and plug-in hybrid electric vehicles are both treated as "new energy vehicles."

2.4. Guangzhou. Unlike Beijing, Tianjin, and Shanghai, Guangzhou is not a province-level municipality. While, Guangzhou government began to limit vehicle purchase very early since August 2012 [36]. The regulation in Guangzhou is similar to that in Tianjin. Lottery and auction both exist, and conventional and energy-saving cars are in separate pools. The numbers of plates released every year in Guangzhou are shown in Figure 8. Unlike Beijing and Tianjin, there is neither significant drop nor booms in quantity. The fluctuations since 2013 are very small. Besides, the ratios of private to business are also stable in the past six years.

Auction accounts for around $40 \%$ plate quota. With the growth of energy-saving cars, fewer plates were prepared for conventional cars. In 2018, energy-saving cars occupy around $10 \%$ and conventional cars take half of the quota. Since the end of 2015, the demand for private energy-saving cars began to surpass the supply, and since July 2017, the demand for business energy-saving cars also exceeded the supply. Only the numbers of conventional internal combustion engine vehicles and energy saving vehicles are limited by the government. The applicants also have to own no cars before lottery or auction for conventional or energysaving vehicle plates. Individuals and companies can apply plates for "new energy vehicles" directly. Battery electric cars and plug-in hybrid electric vehicles are both treated as "new energy vehicles."

\section{Methods and Data}

The predictions of vehicle sales and stock are classic topics. Most of researches in China are focused on national wide study, due to the variation in provincial level as mentioned before $[12,14,37,38]$. Vehicle ownership per 1000 people is usually treated as one indicator which is highly related to economic development, as shown in Table 1. Thus, in this study, private vehicle ownership per thousand people and GDP per capita are used to predict vehicle stock without purchase limits in Beijing, Tianjin, and Guangzhou. The difference between fitting results and actual values is considered as the impact of purchase restriction regulations. Gompertz and Logistic are the most popular models widely applied to fit the relationship between economic factors and vehicle ownership [16, 18, 20, 27-29].

Vehicle ownership per 1000 people is considered as a factor to evaluate the development of automotive industry in certain place, while this factor usually included both passenger vehicles and commercial vehicles. Purchase restriction 


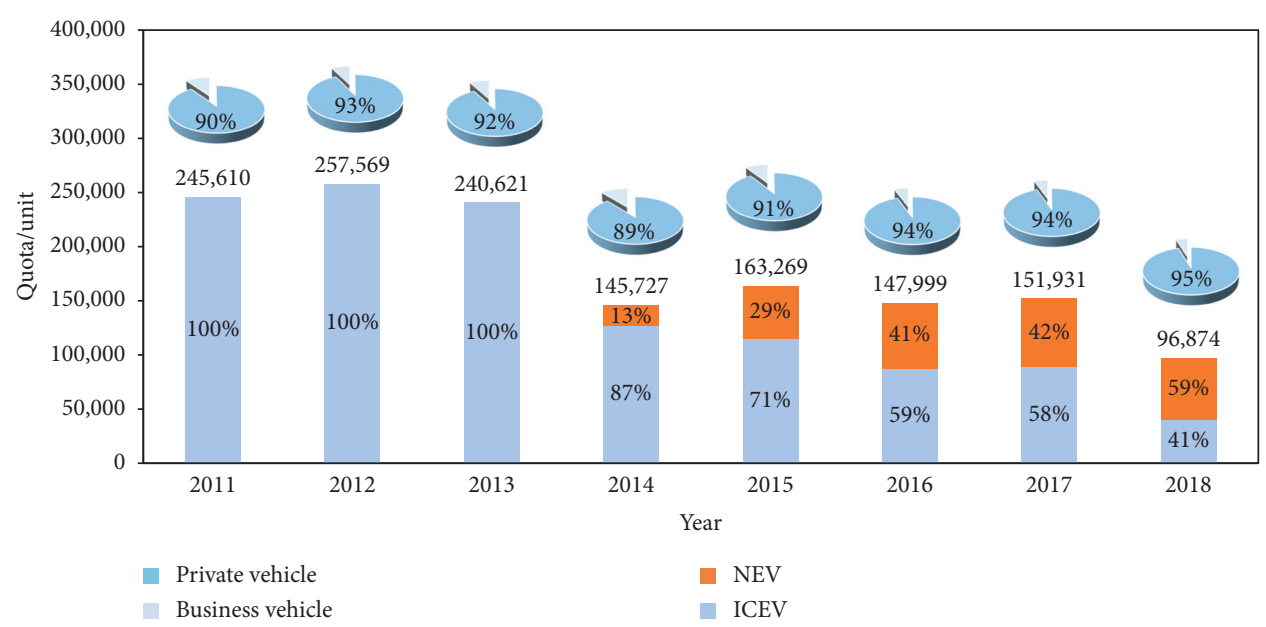

FIgURE 3: The number of plates issued every year in Beijing under the purchase restriction policies (1: internal combustion engine vehicle (ICEV); 2: new energy vehicle (NEV)).

regulations are only applied to passenger vehicles. Thus, we decide to set models to fit the relationship between private passenger vehicle ownership and economy development. The logistic curve is used in this study, as shown in equation (1). Actual data from 2002 in each city mentioned before are used to support the reliability of functions. Figure 9 exhibits the actual values and fitted values based on the logistic model with a very high fitting precision:

$$
y=\frac{a}{1+b e^{-c x}}
$$

where $y$ represents car ownership per thousand people, $x$ represents the economic indicator, GPD per capita; $a$ represents the saturation level of vehicle ownership; and $b$ and $c$ are constants, which decide the shape of the curve.

GDP per capita is always used as an independent variable. GDP and population in each city are obtained from National Statistical Bureau and local yearbooks [26, 39-41]. As China's economy development enters the new stage, GDP growth in China gradually slows down. The number of permanent resident population, instead of registered population, is used in this study. First, with the growing mobility of population, registered people cannot represent the real number of people who live in the city. Then, permanent resident population is the group of people who need and drive cars in the city for daily commute and trips. Finally, purchase limit regulations in these cities are all permit resident under certain conditions to apply for plates.

As for the vehicle stock, though recently the economy in China does not increase as fast as past decades, the vehicle stock still grows dramatically. The data of vehicle ownership used in this article are obtained from city yearbooks published by local governments or China Statistical Yearbooks [26, 40]. Because direct data resource is lacking and medium and large passenger vehicles are always treated as buses for revenue, instead of private use, the sum of private mini and small passenger vehicles is considered as the number of private passenger cars. The upper bound of private passenger car ownership per 1000 people is difficult to be decided, because most predictions are given for all vehicle fleet.
Comprehensively concluding previous studies and recent economic situation and analyzing the proportion of passenger cars in the whole vehicle fleet, the upper bound of private passenger car ownership, $a$, is set as 300 units per 1000 people.

\section{Results and Discussion}

4.1. Results. The numbers of issued plates per thousand people in each year are shown in Figure 10. Different cities exhibit different results and trends. Due to the significant drop in issued plates, the number of issued plates per thousand people in Beijing is also on the decline trend. Starting in 2014, this value remained to be 6 to 7 with small fluctuations. In Tianjin, the number of new plates per thousand people increases gradually, from 5.3 in 2014 to 5.9 in 2017. The results in Shanghai also exhibit growth trend. Due to the relatively stable population of Shanghai in recent years, the number of issued plates and the result of per thousand people basically show the same trend. Guangzhou is the only city where the results had been maintained in a downward trend. The quantity of private passenger vehicle plates issued in Guangzhou remained at a regular level. The numbers of issued plates per thousand people in all of these cities are tending to the same value.

The car ownerships per thousand people in Beijing, Tianjin, and Guangzhou are calculated using the logistic model as mentioned in the Section 3. Because Shanghai began to introduce its purchase restriction too early, it is not applicable to apply the logistic model any more. The difference between model results and actual values is shown in Figure 11. The introduction of purchase restriction exhibited significant effects on vehicle ownership. With the increase of GDP per capita, the private passenger vehicle ownership did not surge accordingly due to the purchase restriction policies.

In 2011, the first year Beijing government began to implement the purchase restriction policy; the difference between the actual value and predicted value was only 15 vehicles per thousand people. While in 2017, the gap between 


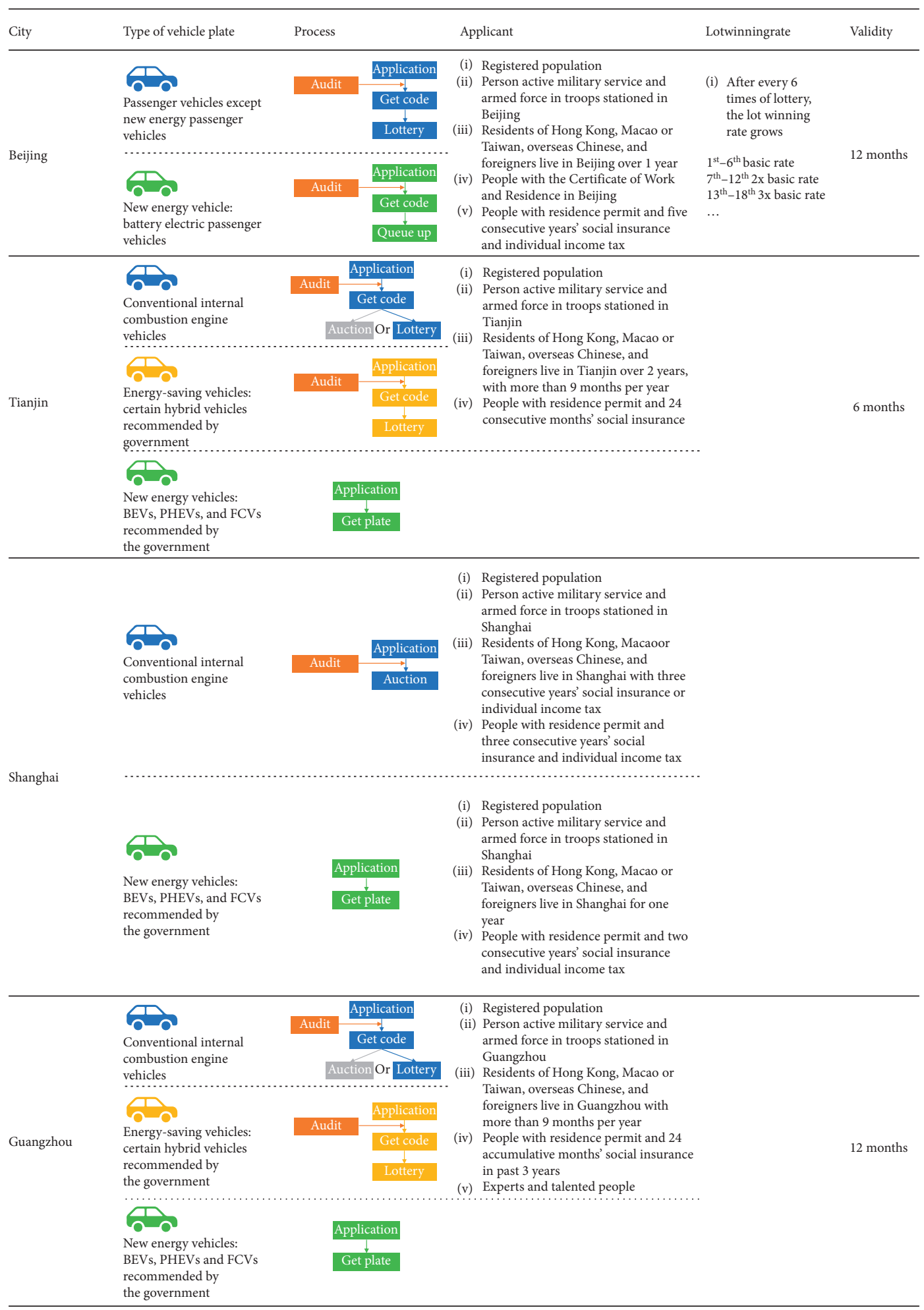

FIGURE 4: Details of vehicle purchase restriction policies in Beijing, Tianjin, Shanghai, and Guangzhou.

these two values widened to 77 vehicles per thousand people. Among all these cities, Beijing has the most stringent policies with fewer and fewer issued license plates, but there is still small increase in the ownership per thousand people. One of the reasons is the total number of plates is still increasing with limited new ones. The other reason is the population in
Beijing is relatively stable in recent years. Besides, lots of plates were issued by the government at the beginning three years.

In Tianjin and Guangzhou, new energy vehicle owners can directly apply for plates. Therefore, it will be more difficult to control vehicles numbers. While, in Tianjin, private passenger vehicle ownership per thousand people experienced 


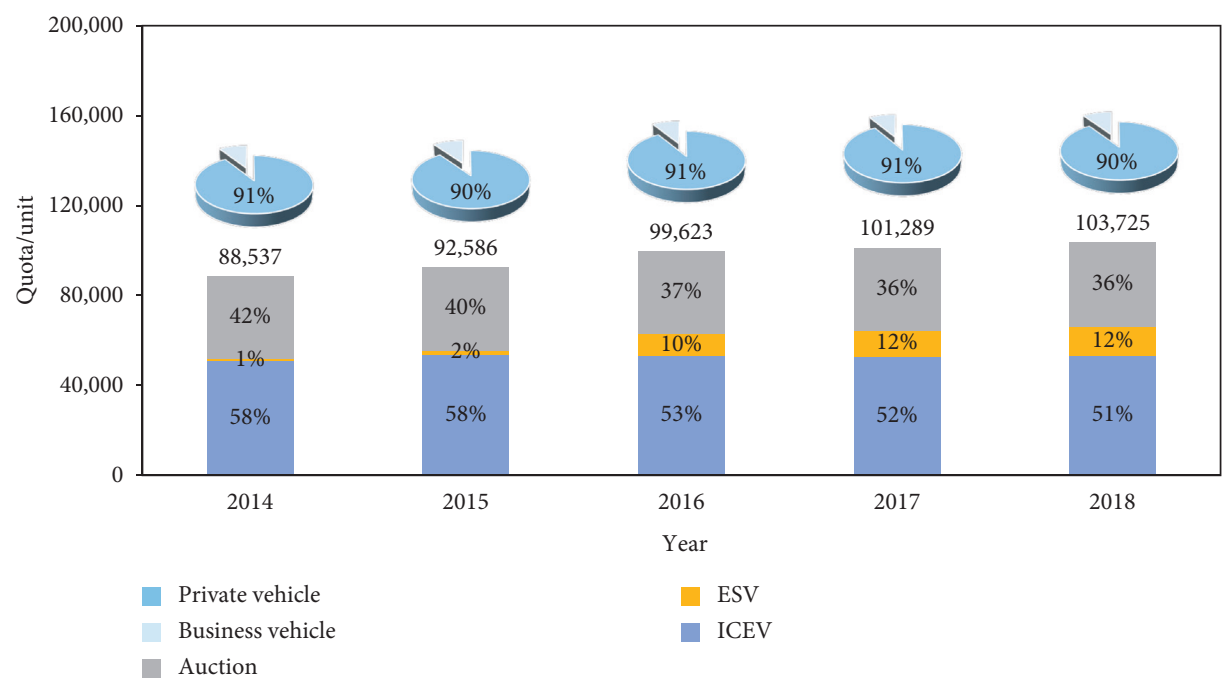

FIgURe 5: The number of plates issued every year in Tianjin under purchase restriction policies.

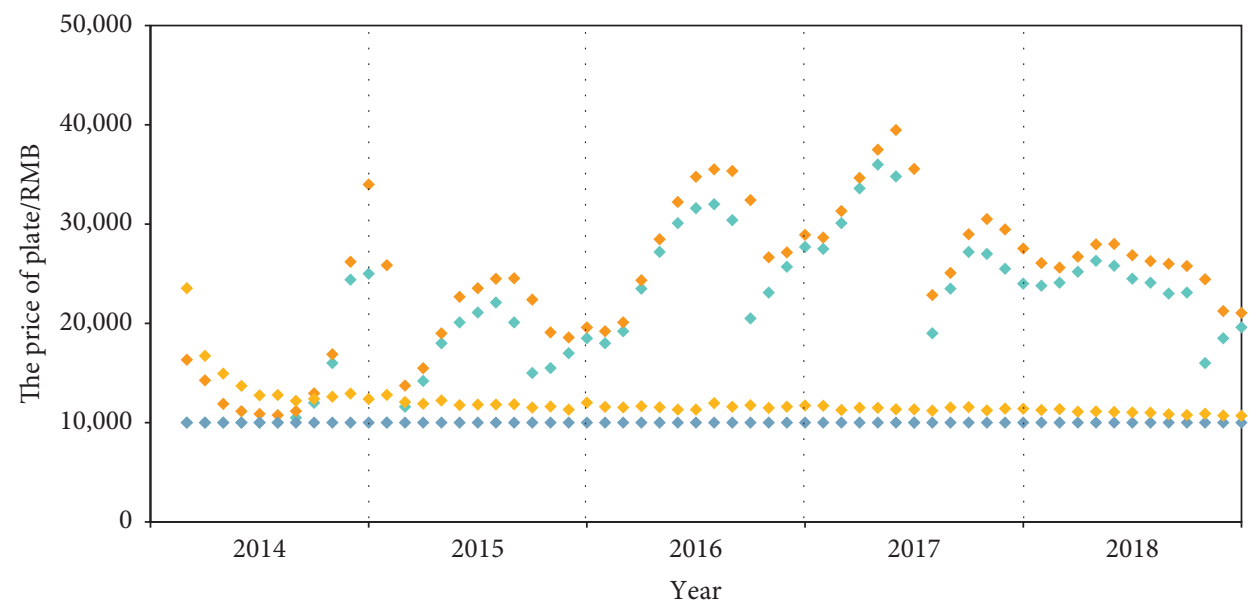

- Average price for private passenger car plate Average price for business passenger car plate

- Lowest price for private passenger car plate $\quad$ Lowest price for business passenger car plate

Figure 6: Price of private and business plates in Tianjin by auction.

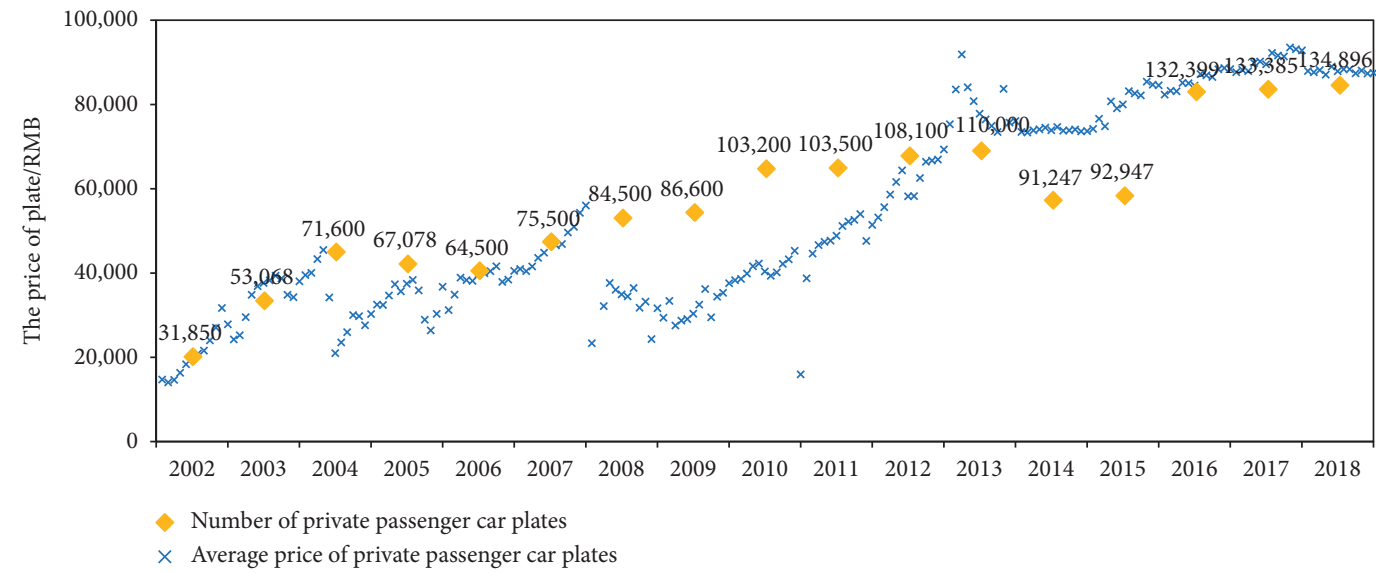

FIGURE 7: Number and average price of private passenger car plates in Shanghai. 


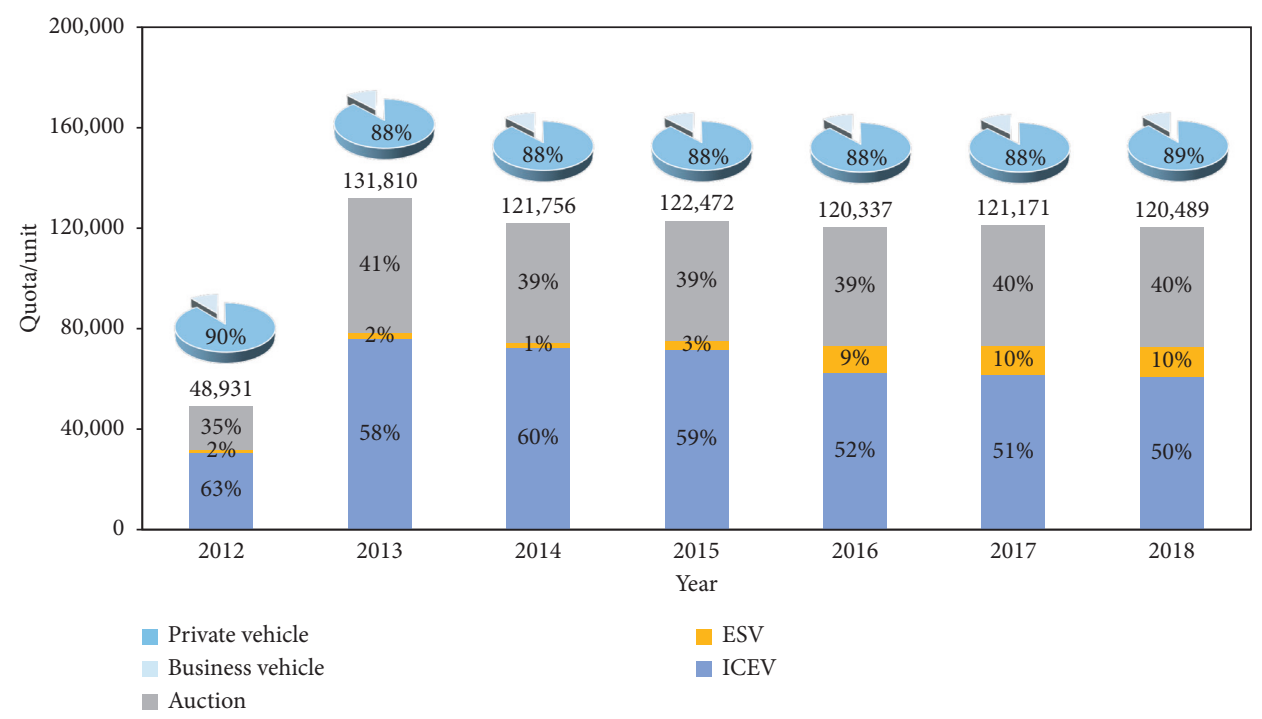

FIGURE 8: The number of plates issued every year in Guangzhou under purchase restriction policies.
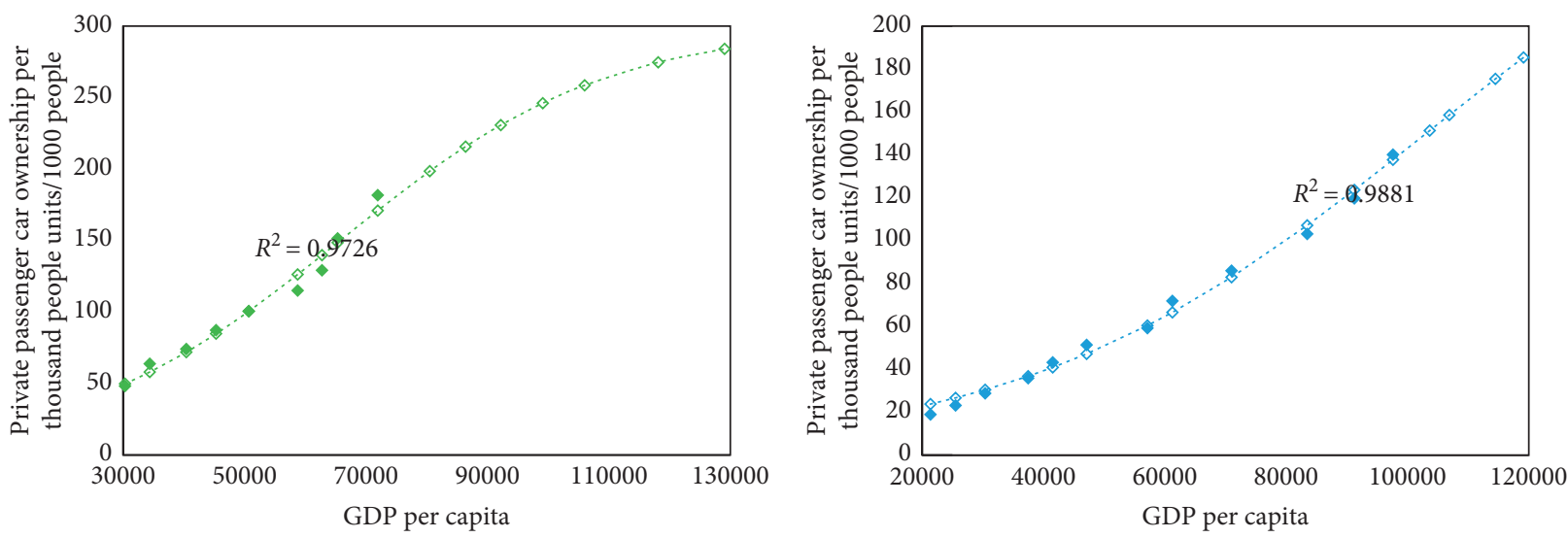

- Actual value

- Actual value

$\diamond$ Fitted value

$\diamond$ Fitted value

(a)

(b)

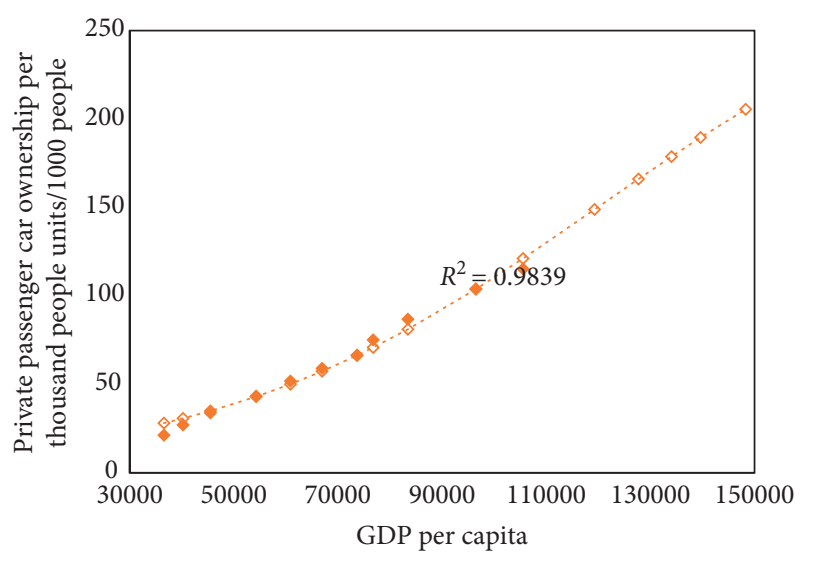

- Actual value

$\diamond$ Fitted value

(c)

FIGURE 9: Actual and fitted values of private passenger vehicle ownership based on GDP per capita in (a) Beijing, (b) Tianjin, and (c) Guangzhou. 


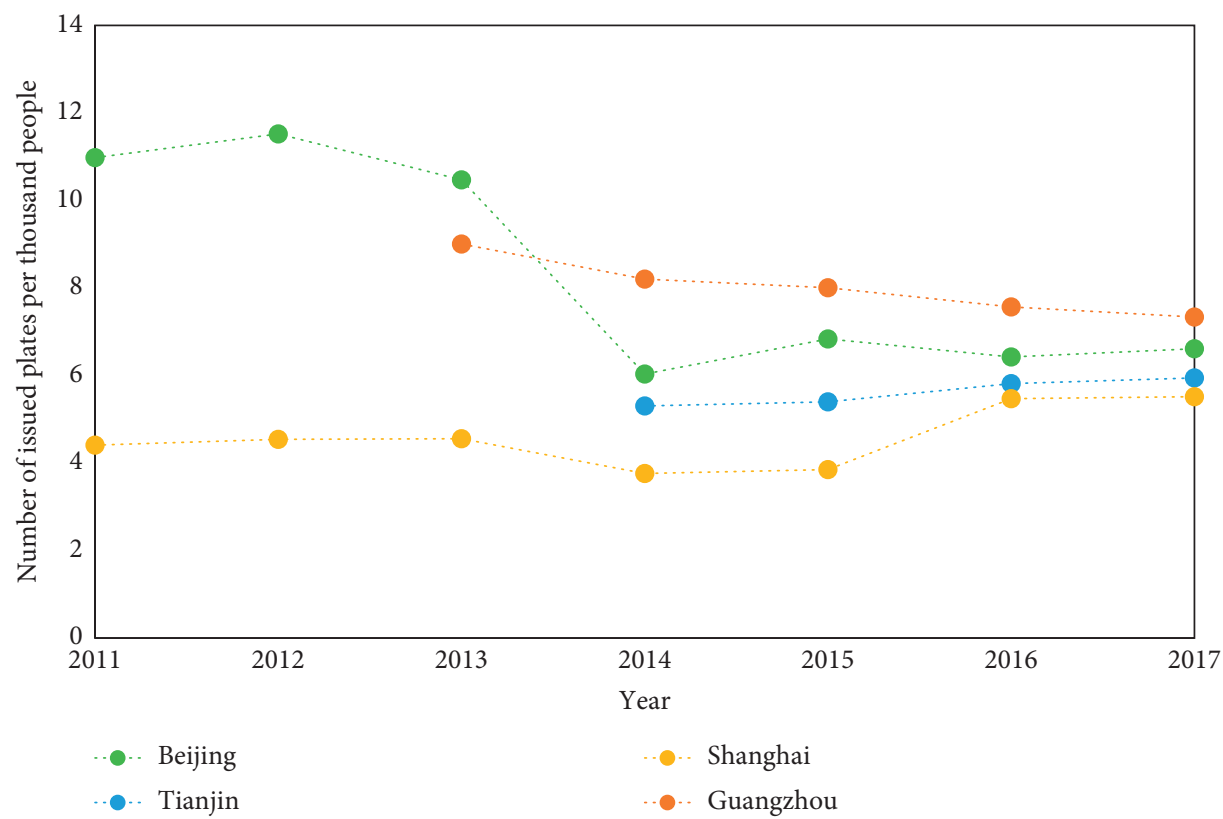

FIgURE 10: The number of issued plates per thousand people in Beijing, Tianjin, Shanghai, and Guangzhou.

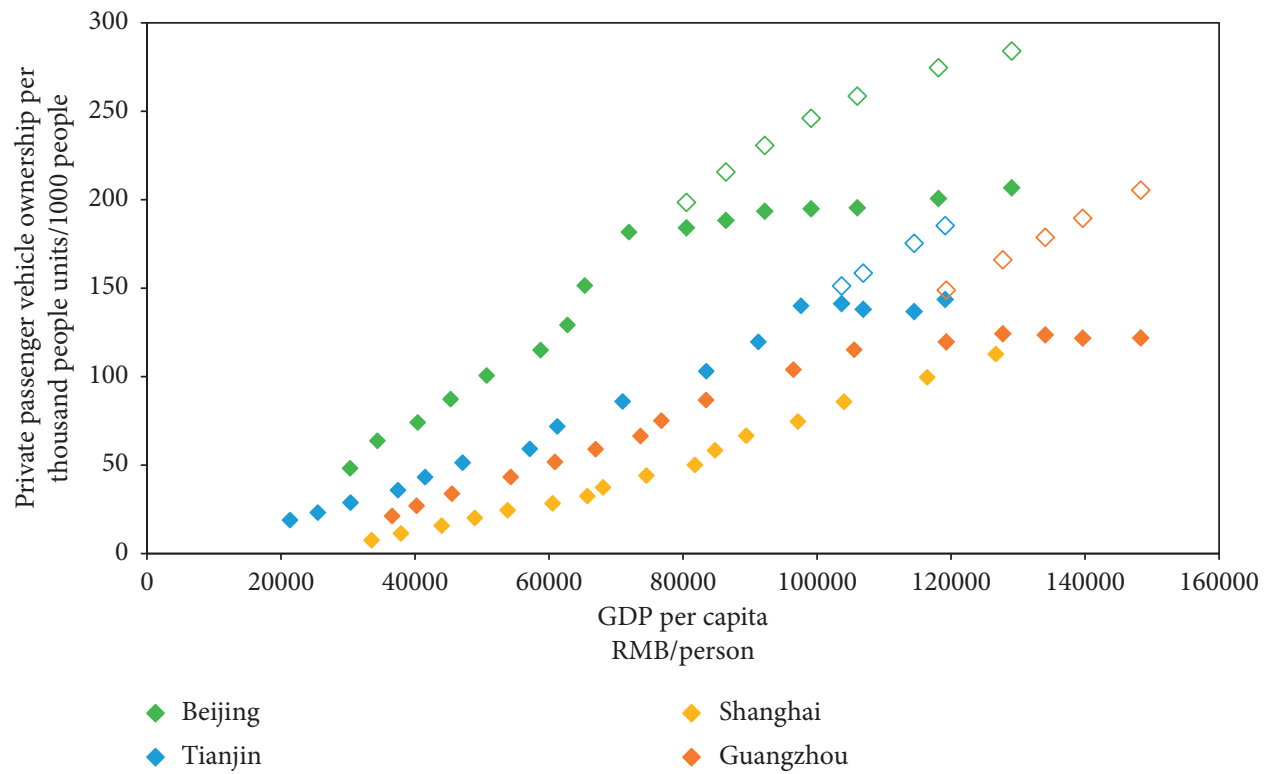

FIGURE 11: Actual and fitted private passenger vehicle ownership per thousand people (unfilled diamonds represent the fitted results with no vehicle purchase restriction policies and filled ones represent the actual values).

first decreases then increases, but the overall fluctuation is not obvious. The ownership per thousand people remained around 140 units per thousand people. The population in Tianjin has also entered a saturated stage. The vehicle stock did not increase much. Thus, the restriction policies showed a remarkable result. The gap between actual and theoretical values increased from 10 in 2014 to 41 in 2017. Unlike Tianjin, in Guangzhou, the vehicle stock still increases. Meanwhile, the population in Guangzhou also keeps rising. As a result, the ownership per thousand people remained steady.

Shanghai, unlike other cities, began to control the number of vehicles in a very early time. Therefore, it is difficult to evaluate the impact since 2002. On the other hand, as shown in Figure 11, with the same GDP per capita, Shanghai's car ownership per thousand people is indeed relatively low, compared with other cities. This fact proves the validity of policies. While the growth rates of private passenger car ownership per thousand people in Shanghai are steeper than those in other cities. The car ownership per thousand people in Shanghai nearly reached the level of that in Guangzhou in 2017. More measures or stringent policies should be considered by the government in Shanghai.

Figure 12 exhibits the actual and theoretical vehicle stocks in Beijing, Tianjin, and Guangzhou. The size of circles 


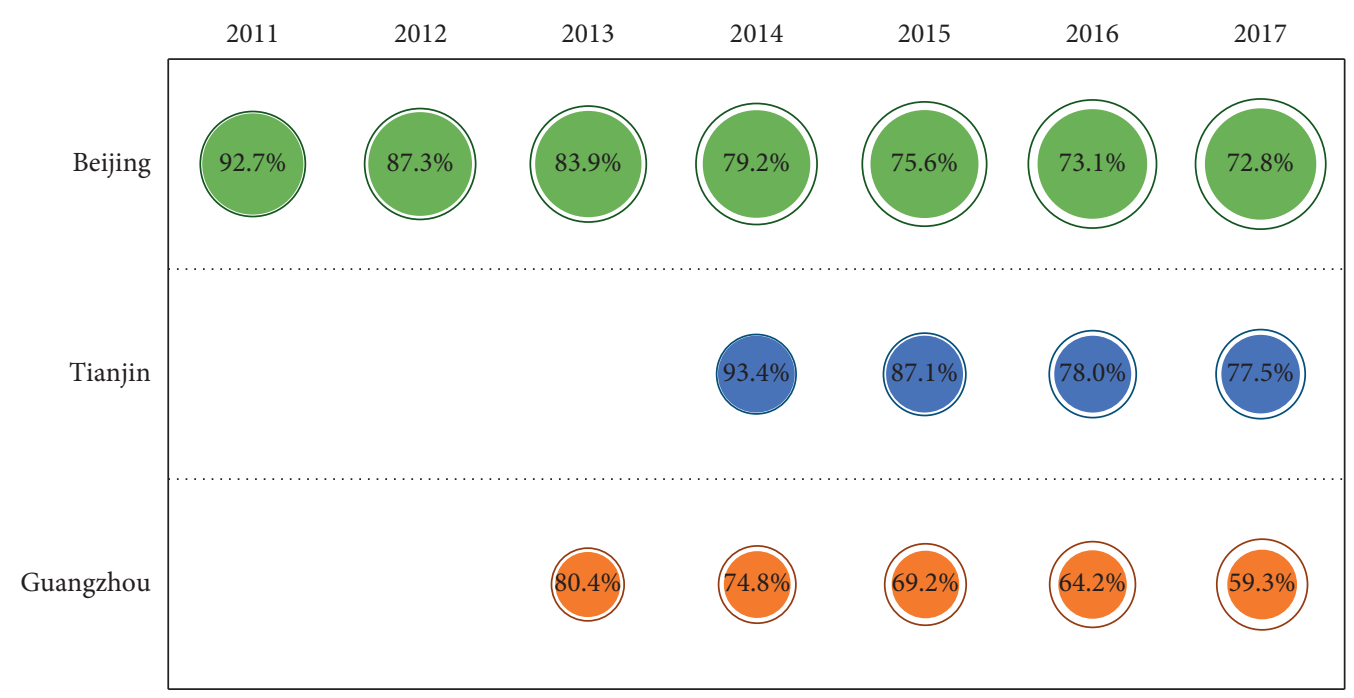

Figure 12: Actual and fitted values of vehicle stock in Beijing, Tianjin, and Guangzhou.

with outline represents the actual value, and the size of circles with solid color shows the theoretical ones. The percentages in the middle indicate the proportions. Unlike car ownership per thousand people, vehicle stock is a macro result. It ignores the differences in population and economy but provides the reference for market size in each city. Though Beijing introduced purchasing restriction earlier, its impacts on vehicle stock are not the most prominent. Guangzhou had reduced $40.7 \%$ vehicle stock under the restriction policies in 2017.

4.2. Discussion. The results in different cities exhibit different trends. Purchasing restriction policies vary from each other, and customers in different cities have different needs and purchasing habits. Overall, car purchasing restriction policies do have great impacts on the vehicle stock and ownerships per thousand people.

In Beijing, the number of private passenger vehicle plates is strictly controlled by the government. Though electric vehicle owners enjoy different policies, the plates are also strictly controlled in certain number in recent years. Besides, more quota will be distributed to electric ones to promote the development of electric vehicle industry and reduce the pressure from energy and environment. At the beginning of purchasing restriction, there were too many issued plates. Therefore, the impacts were not obvious. From 2011 to 2013, around 250 thousand plates were released every year, far more than other cities. Thus, the private car ownership per 1000 people still grew in those year. After 2014, the population in Beijing remained in a relatively stable level, so the ownership also continuously increased slightly. Overall, the effects of purchasing restriction policies were not prominent due to several reasons, and the policies will become stricter and stricter in Beijing.

Plate delivery policies in Tianjin and Guangzhou are almost the same. Lottery and auction means are combined. The number of license plates in both cities also remained at a relatively stable level each year. At the same time, electric vehicle owners can get plates directly, without queuing, drawing lots, or joining auction. Due to the electric vehicles, the vehicle stock is an uncontrollable issue to some extent. It heavily depends on customers' attitude towards electric cars. From the current situation, the impacts of purchase restriction policies are still obvious. Especially in Guangzhou, the influence is very prominent in the short term. The car ownership per thousand people in these two cities is about the same.

Shanghai is the first city to introduce car purchasing restriction policies. Therefore, under the same GDP per capita, private passenger car ownership per thousand people in Shanghai was less than those in other cities. Unlike Beijing, the number of issued plates in Shanghai followed an increasing trend. The price of plates also fluctuated significantly. Meanwhile, the advantage of early implement policies has disappeared. Car ownership per thousand people in Shanghai experienced a rapid growth and was about to be equal of that in other cities. Besides, electric vehicles enjoy special policies, so it will be more difficult to control the vehicle stock in Shanghai.

Other factors or measures may also have impacts on the number of plates. First, car scrappage is a regular thing. However, due to the purchasing restriction policies, residents would not like to abandon plates with disused vehicles. License plates become scarce resources. Replacement will happen, instead of scrappage. Thus, vehicle scrappage will not have great influence on vehicle stock. Then, other driving forces, like limited parking space, high parking fees, long congestion time, and congestion charge, all can reduce people's desire to buy cars and lead to decline in vehicle sales and stock. While, according to current situation, the vehicle plates are in a state where demand is greater than supply. Therefore, these factors may only have impacts on individual purchase choices not on the whole market sales. In summary, only car purchasing restriction policy is treated as the main resistance force for vehicle stock growth.

4.3. Policy Recommendations. In conclusion, the effects of policies also vary greatly among Beijing, Tianjin, Shanghai, 
and Guangzhou. Though only several cities apply purchasing restriction policies in current circumstance, policymakers should pay more attentions to vehicle ownership per thousand people and stock to relieve the pressure of traffic, energy, and environment. Following are some recommendations as references:

(i) Because of economic development and customer preferences, it is impossible for cities to unify policies. The government should formulate purchasing restriction policies with local characteristics according to local conditions.

(ii) With significant results of controlling vehicle number, policymakers still need to take more factors into consideration to formulate quantity and method according to demand. For example, though the sharp decline in plate number in Beijing effectively controlled the vehicle stock, the sudden change did not get a good feedback from residents.

(iii) Cities, like Beijing, may take market means into account. Therefore, residents can have more choices. It will not happen that people have an urgent need for a car but cannot get a license plate. Shanghai, Tianjin, and Guangzhou already have made examples and shown good results.

(iv) Customers are not so keen on buying electric cars. Even if the license plates of electric vehicle are easier to get, the purchase restriction policy can still limit the car ownership per thousand people to a large extent. However, policymakers should be careful in the future. With the development of electric cars, more people may consider and choose to buy electric ones.

(v) Encouraging residents to purchase vehicles will do benefits to economy but not to traffic congestion and energy consumption. Policymakers may consider new ideas to release these pressures, like limitation on travelling instead of purchasing.

(vi) Growth of vehicle stock still will cause more energy consumption or emissions. Introducing alternative fuel vehicles and fuel economy regulations will continuously play their important roles to solve the problem of energy security and climate change.

\section{Conclusion}

By comparing the results under policies and theoretical values, the impacts of car purchasing restriction policies in Beijing, Tianjin, Shanghai, and Guangzhou are analyzed.

(i) Due to the energy, environment, and traffic problems caused by increasing vehicles, some first-tier cities in China issued vehicle purchase restriction policies to limit the number of vehicles. Shanghai is the first one to introduce restriction policies in 1994, followed by Beijing, Guiyang, Guangzhou, Tianjin, Shenzhen, and Hangzhou. Policies in cities vary from each other, because of various political characteristics, economic development, residents' travel demand, etc. The governments delivered plates by one or more ways of lottery, queuing, and auction. Electric vehicles are also treated differently.

(ii) Purchasing restriction policies have effectively limited the growth of private passenger vehicles. There was little increase or fluctuation in private passenger vehicle ownership per 1000 people in Beijing, Tianjin, and Guangzhou after the implementation of policies. The ownership no longer rose with GDP per capita growth. This is contrary to some previous prediction, especially researches in determining energy demand or emissions of vehicle fleet. Therefore, it is necessary to take purchasing restriction policies into consideration in future studies.

(iii) Because Beijing and Tianjin are municipalities, policies' impact is obvious in provincial level. While Guangzhou's influence on Guangzhou Province is not outstanding. The influence of restrictions on national vehicle stock is not prominent either. However, as more cities begin to issue purchase restriction policies, national vehicle stock may be affected. There is still a big gap between plates supply and residents' demand.

(iv) Meanwhile, with present constant vehicle ownership per thousand people, governments should think about how to meet residents' increase travel demand with certain private car ownership per thousand people. Besides, how much ownership is reasonable is also a key point. This will also affect the number of license plates issued in the future.

(v) The vehicle stock still kept rising, and it will keep on leading to more energy consumption and emissions. Actually, encouraging car purchase can promote economic growth. The problems caused by large amounts of cars can be considered from different point of views, like travel restriction and congestion fee. Purchasing restriction policies are not the only solutions.

(vi) In most of the cities, electric car owners can get plates directly without lottery, queuing, or auction. While free plates for electric vehicles do not lead to large amount of vehicle sales in those cities. With the development of technology, more people may change their minds to choose electric cars. Thus, in the future, they may also cause serious problems. Policymakers should pay more attention to and carry out new policies for electric cars in advance.

\section{Data Availability}

The data used to support the findings of this study are included within the article.

\section{Conflicts of Interest}

The authors declare that they have no conflicts of interest. 


\section{Acknowledgments}

This study is sponsored by the National Natural Science Foundation of China (71774100, 71690241), Tsinghua-Rio Tinto Research Center for Resources Energy and Sustainable Development.

\section{References}

[1] Y. Y. Feng, S. Q. Chen, and L. X. Zhang, "System dynamics modeling for urban energy consumption and $\mathrm{CO}_{2}$ emissions: a case study of Beijing, China," Ecological Modelling, vol. 252, pp. 44-52, 2013.

[2] L. Schipper and W. Ng, "Rapid motorization in China: environmental and social challenges," Journal of Separation Science, vol. 37, no. 5, pp. 488-494, 2004.

[3] IEA, $\mathrm{CO}_{2}$ Emissions from Fuel Combustion Highlights 2017, International Energy Agency, Paris, France, 2017, http://www. iea.org/publications/freepublications/publication/co2-emissionsfrom-fuel-combustion-highlights-2017.html>.

[4] Beijing Transport Institute, Beijing Traffic Development Annual Report in 2018, Beijing Transport Institute, Beijing, China, 2018, http://www.bjtrc.org.cn/InfoCenter/NewsAttach/2018年 北京交通发展年报.pdf.

[5] J. Dargay and P. Vythoulkas, "Estimation of a dynamic car ownership model: a pseudo-panel approach," Journal of Transport Economics and Policy, vol. 33, no. 3, pp. 287-302, 1999.

[6] J. M. Dargay, "The effect of income on car ownership: evidence of asymmetry," Transportation Research Part A: Policy and Practice, vol. 35, no. 9, pp. 807-821, 2001.

[7] J. M. Dargay, "Determinants of car ownership in rural and urban areas: a pseudo-panel analysis," Transportation Research Part E: Logistics and Transportation Review, vol. 38, no. 5, pp. 351-366, 2002.

[8] H. Kim and E. Kim, "Effects of public transit on automobile ownership and use in households of the USA," Review of Urban \& Regional Development Studies, vol. 16, no. 3, pp. 245-262, 2004.

[9] M. Chamon, P. Mauro, and Y. Okawa, "Mass car ownership in the emerging market giants," Economic Policy, vol. 23, no. 54, pp. 243-296, 2008.

[10] J. Dargay and D. Gately, "Income's effect on car and vehicle ownership, worldwide: 1960-2015," Transportation Research Part A: Policy and Practice, vol. 33, no. 2, pp. 101-138, 1999.

[11] J. Dargay and G. Sommer, "Vehicle ownership and income growth, worldwide: 1960-2030," The Energy Journal, vol. 28, no. 4, pp. 143-170, 2007.

[12] J. Han and Y. Hayashi, "Assessment of private car stock and its environmental impacts in China from 2000 to 2020," Transportation Research Part D: Transport and Environment, vol. 13, no. 7, pp. 471-478, 2008.

[13] H. Hao, H. Wang, and R. Yi, "Hybrid modeling of China's vehicle ownership and projection through 2050," Energy, vol. 36, no. 2, pp. 1351-1361, 2011.

[14] H. Huo and M. Wang, "Modeling future vehicle sales and stock in China," Energy Policy, vol. 43, pp. 17-29, 2012.

[15] O. Johansson and L. Schipper, "Measuring the long-run fuel demand of cars: separate estimations of vehicle stock, mean fuel intensity and mean annual driving distance," Journal of Transport Economics and Policy, vol. 31, no. 3, pp. 277-292, 1997.

[16] H. Lu, H. Ma, Z. Sun, and J. Wang, "Analysis and prediction on vehicle ownership based on an improved stochastic
Gompertz diffusion process," Journal of Advanced Transportation, vol. 2017, p. 8, 2017.

[17] Y. Wang, J. Teter, and D. Sperling, "China's soaring vehicle population: even greater than forecasted?" Energy Policy, vol. 39, no. 6, pp. 3296-3306, 2011.

[18] T. Wu, H. Zhao, and X. Ou, "Vehicle ownership analysis based on GDP per capita in China: 1963-2050," Sustainability, vol. 6, no. 8, pp. 4877-4899, 2014.

[19] N. Wu, S. Zhao, and Q. Zhang, "A study on the determinants of private car ownership in China: findings from the panel data," Transportation Research Part A: Policy and Practice, vol. 85, pp. 186-195, 2016.

[20] Z. Yang, P. Jia, W. Liu, and H. Yin, "Car ownership and urban development in Chinese cities: a panel data analysis," Journal of Transport Geography, vol. 58, pp. 127-134, 2017.

[21] J. Ma, X. Ye, and C. Shi, "Development of multivariate ordered probit model to understand household vehicle ownership behavior in Xiaoshan District of Hangzhou, China," Sustainability, vol. 10, no. 10, p. 3660, 2018.

[22] D. Potoglou and P. S. Kanaroglou, "Modelling car ownership in urban areas: a case study of Hamilton, Canada," Journal of Transport Geography, vol. 16, no. 1, pp. 42-54, 2008.

[23] S. B. Nugroho, E. Zusman, R. Nakano et al., "Exploring influential factors on transition process of vehicle ownership in developing Asian city, a case study in Bogor city Indonesia," in in Proceedings of the 2017 IEEE 20th International Conference on Intelligent Transportation Systems (ITSC), pp. 674-679, Yokohama, Japan, October 2017.

[24] The Ministry of Public Security of the People's Republic of China, In 2018, Car Ownership in China Exceeded 200 Million for the First Time, The Ministry of Public Security of the People's Republic of China, Beijing, China, 2019, http://www. mps.gov.cn/n2254098/n4904352/c6354939/content.html.

[25] China Association of Automobile Manufacturers, Brief Analysis of Production and Sales of Automobile Industry in December, 2018, China Association of Automobile Manufacturers, Beijing, China, 2019, http://www.caam.org.cn/ zhengche/20190114/1505221206.html.

[26] National Bureau of Statistics, China Statistical Yearbook 2003-2018, China Statistics Press, Beijing, China, 2019.

[27] J. Shi and M. Jian, "Analysis of car ownership growth trend in China under the purchasing restriction policy," in Proceedings of the International Conference of Transportation Professionals, pp. 3563-3574, Beijing, China, July 2015.

[28] Y. Wu, S. Zhang, J. Hao et al., "On-road vehicle emissions and their control in China: a review and outlook," Science of The Total Environment, vol. 574, pp. 332-349, 2017.

[29] B. Zheng, Q. Zhang, J. Borken-Kleefeld et al., "How will greenhouse gas emissions from motor vehicles be constrained in China around 2030?" Applied Energy, vol. 156, pp. 230-240, 2015.

[30] S. Feng, Q. Li, and D. Xu, "The private car license plate auction in Shanghai: macro-effectiveness and micro-mechanisms," in Proceedings of the International Conference of Transportation Professionals, pp. 118-129, Beijing, China, July 2012.

[31] Beijing Municipal Commission of Transport, Detailed Rules for the Implementation of Interim Provisions on the Regulation of the Number of Small Passenger Cars in Beijing, Beijing Municipal Commission of Transport, Beijing, China, 2017, https://www.bjhjyd.gov.cn/bszn/201819/1515465021612_1. html.

[32] The People's Government of Beijing Municipality, Interim Provisions on the Regulation of the Number of Small Passenger Cars in Beijing, The People's Government of Beijing 
Municipality, Beijing, China, 2010, https://www.bjhjyd.gov. cn/bszn/20101227/1293421253200_1.html.

[33] Tianjin Transport Commission, Regulation and Control Measures for the Total Quantity of Small Cars in Tianjin, Tianjin Public Security Bureau, Tianjin, China, 2014, http:// www.tjjttk.gov.cn/glbf/.

[34] Shanghai Municipal Development \& Reform Commission, Measures to Encourage the Purchase and Use of New Energy Vehicles in Shanghai, Shanghai Municipal Development \& Reform Commission, Shanghai, China, 2018, http://www. shanghai.gov.cn/nw2/nw2314/nw2319/nw12344/u26aw55046. html.

[35] Shanghai Municipal People's Government, Regulations on Auction Management of Passenger Car Quotas in Shanghai, Shanghai Municipal People's Government, Shanghai, China, 2016, http://chepai.alltobid.com/contents/28/155.html.

[36] Guangzhou Municipal Transport Bureau, Measures for the Control and Management of the Total Amount of Small and Medium Passenger Car in Guangzhou, Guangzhou Municipal Transport Bureau, Guangzhou, China, 2018, https://jtzl.gzjt. gov.cn/index/gbl/201879/1531121317825_1.html.

[37] J. D. Du, W. J. Han, Y. H. Peng, and C. C. Gu, "Potential for reducing GHG emissions and energy consumption from implementing the aluminum intensive vehicle fleet in China," Energy, vol. 35, no. 12, pp. 4671-4678, 2010.

[38] H. Zhang, "The medium and long term forecast of China's vehicle stock per 1000 person based on the Gompertz model," Journal of Industrial Technological Economics, vol. 7, no. 225, pp. 7-23, 2012.

[39] Guangzhou Municipal Statistics Bureau, Statistical Communique of Guangzhou Economic and Social Development 2002-2017, Guangzhou Municipal Statistics Bureau, Guangzhou, China, 2018.

[40] Guangzhou Municipal Statistics Bureau, Guangzhou Statistical Yearbook 2003-2018, China Statistics Press, Beijing, China, 2019.

[41] Guangzhou Municipal Statistics Bureau, Population Scale and Distribution in Guangzhou 2005-2018, Guangzhou Municipal Statistics Bureau, Guangzhou, China, 2019. 


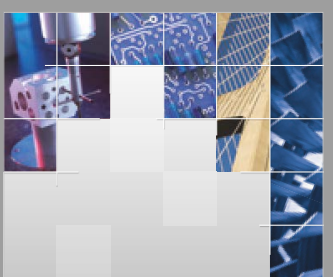

\section{Enfincering}
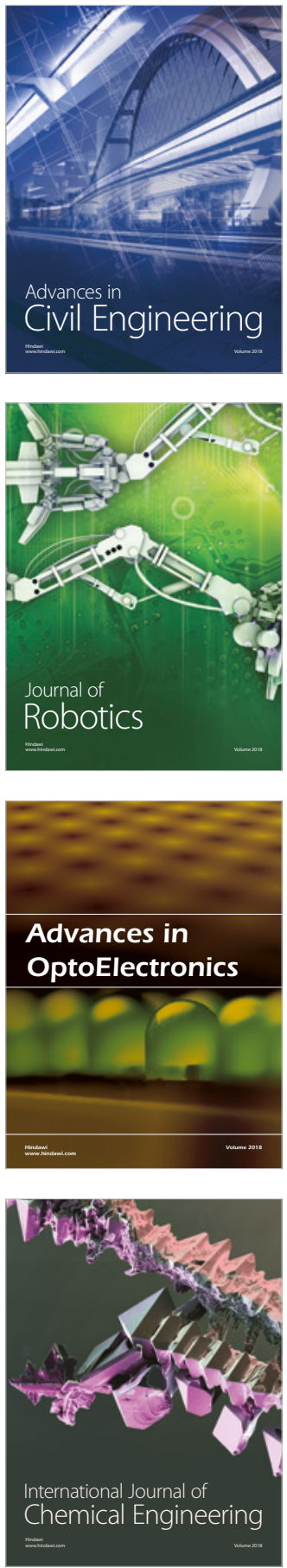

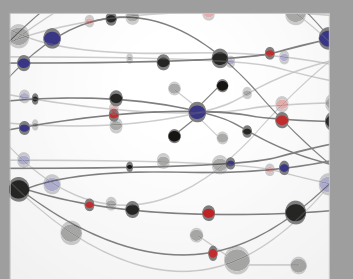

\section{Rotating \\ Machinery}

The Scientific World Journal

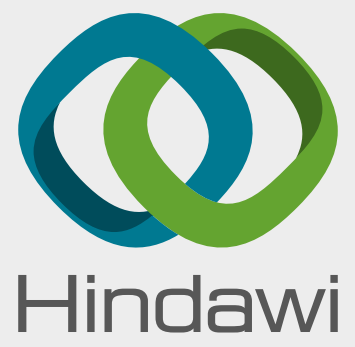

Submit your manuscripts at

www.hindawi.com
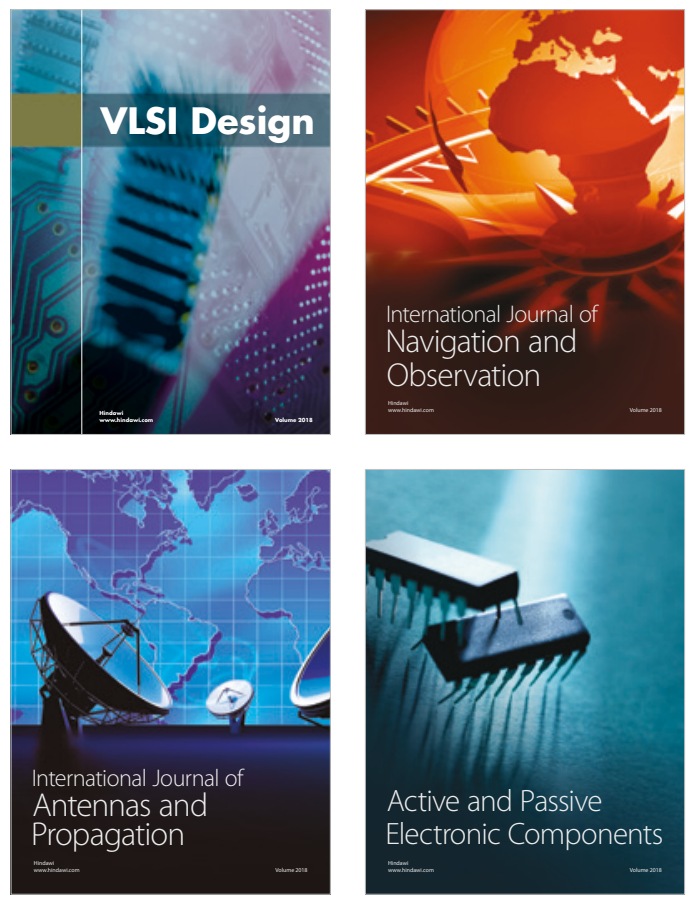
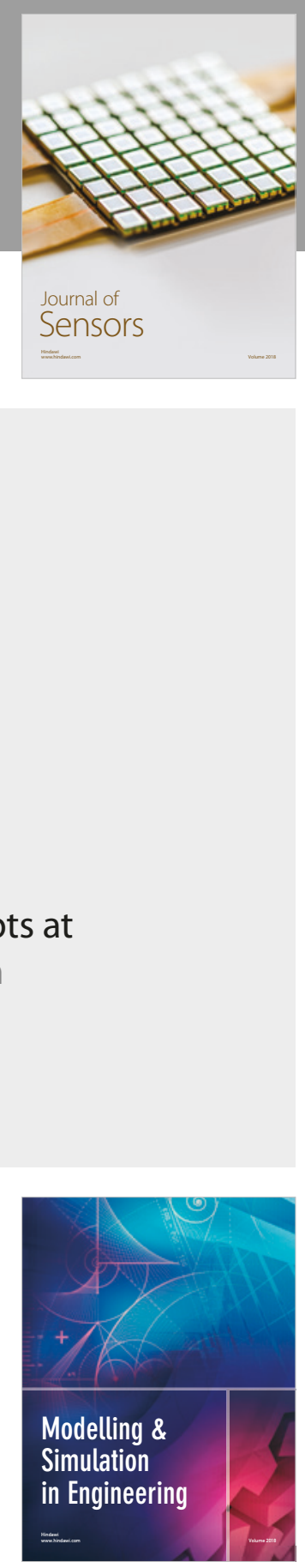

\section{Advances \\ Multimedia}
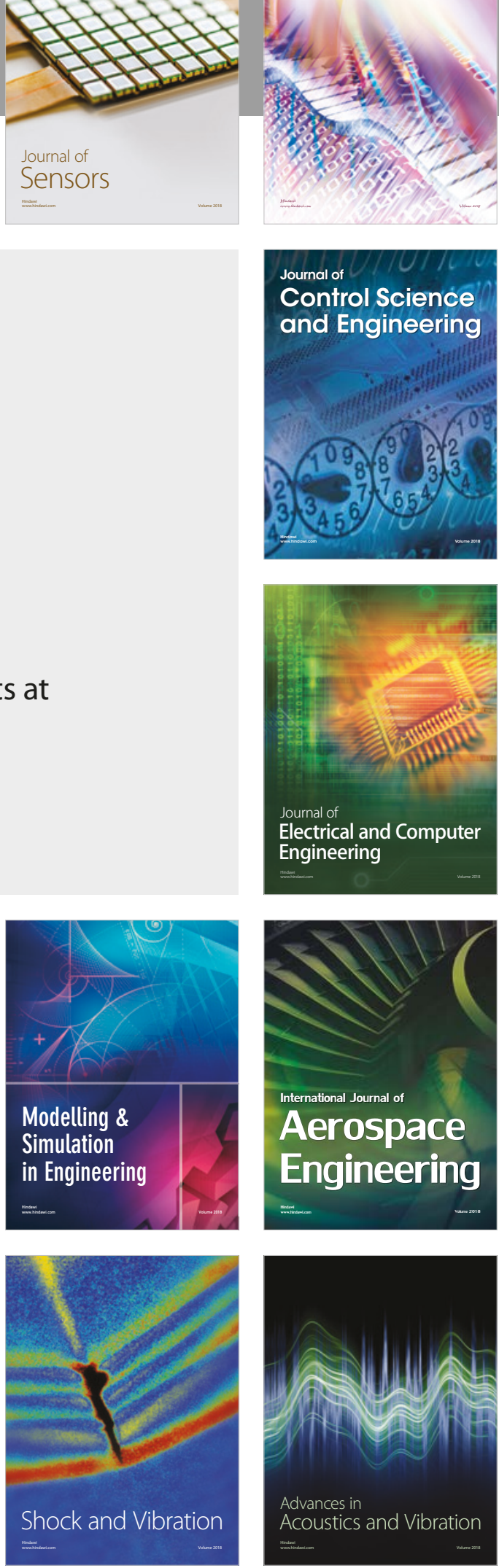